\title{
Monetary policy effectiveness and stock market cycles in ASEAN-5
}

\begin{abstract}
This paper examines the asymmetric effects of monetary policy on real output in Bull and Bear phases of stock market in five ASEAN economies (Malaysia, Singapore, Indonesia, the Philippines and Thailand) using the recently developed pooled mean group (PMG) technique. Stock market cycles are identified by employing Markov-switching models and the rulebased non-parametric approach. Estimating the models using monthly data from 1991:1 to 2011:12, the results show that monetary policy (measured by short-term interest rate) has a negative and statistically significant long-run effect on real output in bull and bear market periods while the effects are stronger in bear periods than bulls. In the short-run, there is not statistically significant relationship between monetary policy and real output. These results are consistent with finance constraints (capital market imperfection) models which predict that monetary policy is more effective during bear periods than bulls.
\end{abstract}

Keyword: Monetary policy; Stock market cycles; Asymmetry; Pooled mean group; Markov switching 